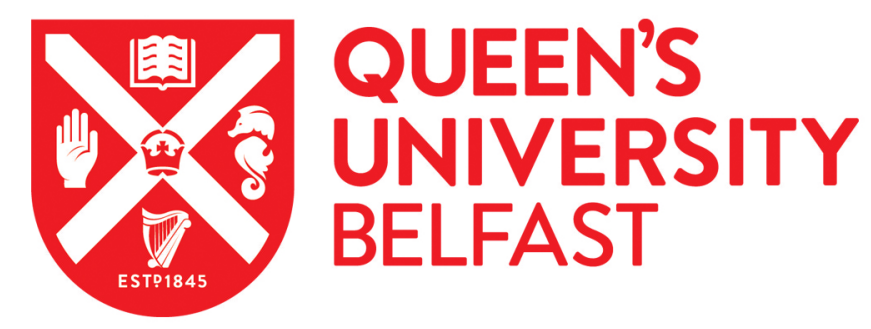

\title{
Prescribed Pain and Mental Health Medication Prior to Suicide: A Population Based Case Control Study
}

O'Neill, S., Graham, B., \& Ennis, E. (2019). Prescribed Pain and Mental Health Medication Prior to Suicide: A Population Based Case Control Study. Journal of Affective Disorders, 246.

https://doi.org/10.1016/j.jad.2018.12.018

Published in:

Journal of Affective Disorders

Document Version:

Peer reviewed version

Queen's University Belfast - Research Portal:

Link to publication record in Queen's University Belfast Research Portal

\section{Publisher rights}

Copyright 2018 Elsevier.

This manuscript is distributed under a Creative Commons Attribution-NonCommercial-NoDerivs License

(https://creativecommons.org/licenses/by-nc-nd/4.0/), which permits distribution and reproduction for non-commercial purposes, provided the author and source are cited.

\section{General rights}

Copyright for the publications made accessible via the Queen's University Belfast Research Portal is retained by the author(s) and / or other copyright owners and it is a condition of accessing these publications that users recognise and abide by the legal requirements associated with these rights.

Take down policy

The Research Portal is Queen's institutional repository that provides access to Queen's research output. Every effort has been made to ensure that content in the Research Portal does not infringe any person's rights, or applicable UK laws. If you discover content in the Research Portal that you believe breaches copyright or violates any law, please contact openaccess@qub.ac.uk. 


\begin{abstract}
Background; Information about prescription medications prior to death by suicide may help us understand the role of medications, illness and service contact in suicide. Aims; Through the use of a novel dataset, this study aims to provide an improved understanding of the relationships between pain medication and mental health medication, suicide and area level deprivation. Methods; Data was included on all deaths by suicide in NI (Northern Ireland) between $1 / 1 / 2012$ and 31/12/2015. Each death was matched to 5 live controls, based on age (the closest match within two years) and gender, resulting in a dataset consisting of 6630 individuals. Four data sources were linked to obtain the final dataset. Results; Suicide linked with and deprivation, with a heightened risk of suicide for 9 months after last prescription of pain medication and for up to two years after last prescription of mental health medication.

Odds ratios for death by suicide were strongest among those with the most recent prescriptions (within 0-3 months) (OR for death by suicide $=12.20$ amongst those with mental health prescription medication; OR for death by suicide=3.69 amongst those with pain medication). These figures support the associations between suicide and pain related conditions, and physical health difficulties. Recent prescriptions are particularly important. Limitations; Received medication prescriptions may not have been taken as recommended. Conclusions; Contact with a clinician to obtain a prescription may present opportunities for intervention. Suicide assessment (and evidence-based suicide specific treatments) may be important for people who are receiving prescribed medication, particularly for a mental illness.
\end{abstract}


Prescribed Pain and Mental Health Medication Prior to Suicide: A Population Based Case Control Study

Suicide is an important cause of preventable death, with over 5668 suicides registered in GB (Great Britain) in 2016 and 297 suicides in NI (Northern Ireland) (NISRA (Northern Ireland Statistics and Research Agency), 2017, ONS (Office for National Statistics), 2017). Across the UK (United Kingdom), NI has the highest suicide rate, followed by Scotland, England and Wales (Samaritans, 2017). Our understanding of the risk factors associated with suicidal behaviour has advanced greatly, but it remains impossible to fully explain or predict the behaviour (Franklin et al., 2017, Klonsky \& May, 2014, Large et al., 2017).

Mental disorders represent a key vulnerability factor for suicidal behaviours (Franklin et al., 2017, O’Connor \& Nock, 2014). However, contemporary models of suicidal behaviour illustrate the ways in which mental disorders can interact with personality and individual differences, cognitive factors, social factors and negative life events to lead to suicidal behaviour (Franklin et al., 2017, O’Connor \& Nock, 2014). Examples of negative life events recognised as risk factors include exposure to trauma, childhood adversities and physical illness (Franklin et al., 2017, O’Connor \& Nock, 2014).

Pharmacological interventions are typically used in treating the symptoms of mental illnesses (Cipriani et al., 2018). The importance of mental disorders and physical illnesses as risk factors for suicidal behaviours has led to attention to how the pharmacological interventions often used to treat the symptoms of these illnesses relate to suicidal behaviours. The expected reduction in vulnerability to suicidal behaviour has been documented following use of these medications (Gibbons et al., 2012). However, results on this front have not been consistent, with suggestions that some may increase suicidality through various mechanisms, particularly in children / adolescents (Sharma et al., 2016) and at the onset of treatment (Wasserman et al., 2012). 
There is increasing recognition in this domain of the need to consider polypharmacy (the simultaneous use of numerous medications), and also the implications of various study designs. Polypharmacy has received limited attention, but it stands to reason that it may be important given that physical illnesses also represent a risk factor for suicidal behaviour as well as mental illnesses (Franklin et al., 2017, O’Connor \& Nock, 2014). Polypharmacy may elevate suicide risk in a number of ways such as increased side effects, greater potential for interactions between medications, and the use of prescribed medications in overdose (Benson et al., 2017). Methodologically, although various methods are available (e.g. case studies, clinical trials etc.), toxicological and medical records of individuals who have died by suicide represents the most effective method of studying this issue (Benson et al., 2017).

One study adopted this method and studied polypharmacy among those who had died by suicide (Benson et al., 2017). Two medication categories, physical and mental health, were identified based on the BNF (British National Formulary) categorisations and an individual's health profile (Benson et al., 2017). Prescribing of medications was prevalent (65.1\%) among individuals who died by suicide, with Latent Class Analyses (LCA) demonstrating considerable polypharmacy (Benson et al., 2017). The latent class analysis revealed three classes of medication use amongst those who had died by suicide. The most common class was baseline/low level of medication use (56.5\%), with mixed medication use (moderate probabilities of being prescribed various physical and mental health medications being second most common at $25.8 \%$, and the use of primarily mental health medication use being the smallest class at $17.7 \%$.

Such findings have important implications in providing insights for practice, and policy decision making, but methodological issues must be considered. A matched control group was not used, and this would be necessary to identify the factors related to suicide (Pouliot \& Leo, 2006). Secondly, deprivation was not considered despite the fact that suicide 
rates in the most deprived areas are three times higher than those in the least deprived areas (Department of Health, 2016). Thirdly, whilst assessment of prescription medication via coronial files was useful, the data was not always complete, and was limited by what the coroner or police record. In addition, the medication profile was not over any specific time periods. The analyses of prescribed medication, undertaken in this study may provide a more accurate picture (Benson et al., 2017). Furthermore, the timeframe in which the medication was prescribed was not explored in relation to death by suicide. This may be important as Lavigne et al. (2012) state that "Studies of prescribing patterns leading up to suicide may identify markers of rising suicide risk that could be used to inform population-level screening and prevention" (p. 565).

Finally, as noted earlier, Benson et al. (2017) documented the importance of considering polypharmacy amongst those who have died by suicide. However, physical health medications were considered in a generic category rather than focusing on any particular category of medications. In the current study we considered pain medications specifically, as pain (physical and psychological) has been linked to increased risk of suicidal thoughts and behaviours via many routes (Calati et al., 2015, Elman et al., 2013, Rizvi et al., 2017, Verrocchi et al., 2016). Firstly, epidemiological studies suggest that mental disorders and physical disorders (including chronic pain conditions) are highly comorbid (Sartorius, 2018). Patients with common mental disorders, such as depression and anxiety often first present to primary care with physical symptoms characterised by pain (Escobar et al., 2006). Secondly, increased pain tolerance has been linked with suicidal behaviour and the acquired capability to enact lethal suicidal behaviour (O’Connor \& Nock, 2014). Thirdly, suicidal behaviour is often conceptualised as a response to psychological pain ('psychache'; Shneidman, 1993) (Elman et al., 2013, Franklin et al., 2017, Meerwijk \& Weiss, 2017, O'Connor \& Nock, 2014) and commentators have argued that this physical and psychological 
pain may share neurocircuitry (Rizvi et al., 2017). In summary, mental illness is associated with suicide, therefore mental health medications are included in the analysis. However, we also wanted to assess whether pain medications were a useful additional way of identifying individuals who were more likely to die by suicide.

Previous studies have also highlighted the usefulness of using linked datasets to study the factors associated with suicide. However, only a few previous studies have linked datasets from multiple healthcare systems to study a wider range of risk factors. For example, Lewis and Sloggett (1998) linked the ONS longitudinal study to NHS (National Health Service) data, whilst Dougall et al. (2014) linked national records data to hospital data to study suicide in Scotland, and Voaklander et al. (2008) linked hospital data with medications data. Although previous studies have utilised linked datasets to study suicide, these studies have not included the variables included here. This study uses a novel dataset to examine patterns of prescription medication (for mental disorders and pain) among those who have died by suicide in comparison with a matched control group, and any patterns relate to deprivation and recency of prescription. This will improve understanding of the risk factors associated with death by suicide.

\section{Method}

\section{Data sources and matching}

The study used a case-control methodology to examine the relationships between prescription of pain and mental health medication, and death by suicide. Data was included on all deaths by suicide in NI between 1/1/2012 and 31/12/2015. Each death was matched to 5 live controls, based on age (the closest match within two years) and gender, resulting in a dataset consisting of 6630 individuals. This matching procedure provided a sufficient sample on which to perform the subsequent analyses. We decided not to match on MDM to allow for the inclusion of this as an independent variable in the subsequent models. Four data sources 
were linked to obtain the final dataset. Deaths by suicide were obtained from the NI General Registrar's database. All deaths from causes other than natural illness in NI are referred to the coroner's office for an inquest, with the majority of inquests completed within a year, after which the death is recorded by the General Registers office (Largey et al., 2002, NISRA, 2012). This study therefore excluded the most recent year's data.

The control group was obtained from the NI General Practitioner Patient Registration Index. This database holds details on all patients registered with a GP in NI, constituting all of the population, as well as age and gender information required for matching. The third source of data, medication information, was obtained from the Enhanced Prescribing database, which holds information on medication dispensing across NI. The date of death of the matched case was used as an index for the medication timeframes. The fourth data source was the NI Multiple Deprivation Measure (MDM), which was obtained from the Northern Ireland Statistics and Research Agency (NISRA).

All NI residents who are registered with a GP practice have a unique identifier (Health and Care Number), which was used along with postcode and age to match the individual level data, with the MDM being matched based on the individuals postcode. The individual level data extraction and linkage was carried out by the Business Services Organisation Honest Broker Service, which provides secure access to anonymised data for ethically approved research. The overall data quality was excellent, with only 59 cases excluded from the final models due to missing data.

\section{Measures}

The following variables were included in the study.

\section{Death by Suicide}

The dependent variable for the study was death by suicide, which was measured as a binary variable, based on ICD-10 codes of: death by intentional self-harm (ICD10: X60-X84, 
Y87.0) and death by events of undetermined intent (ICD10: Y10-Y34, Y87.2).This approach is consistent with the approach taken to measure the official suicide statistics in NI (NISRA, 2012). Not including death by events of undetermined intent would underestimate suicide deaths. Out of a total of 1105 deaths included in the study, 374 were recorded as occurring as a result of poisoning or self-harm of undetermined intent.

\section{Pain and Mental Health Medication Prescription}

For our focal independent variables, we included dummy variables measuring whether or not pain and mental health medication was prescribed and dispensed to each individual in the case and control groups. We measured the timeframe prior to death in which the most recent prescription was made, using time bands of 0 months up to and including 3 months; Over 3 months up to and including 6 months; Over 6 months up to and including 9 months; Over 9 months up to and including 12 months; and over 12 months up to and including 24 months. This variable provided data on both whether or not the patient was dispensed the medication, in addition to how recently it was dispensed. The specific medications included under pain and mental health medications are based on the British National Formulary Classification (BNF), which categorises medications and provides guidance to prescribing healthcare professionals in the United Kingdom (BNF, 2018). The BNF is divided into eight chapters which relate to body systems, with each chapter subdivided into sections relating to medication categories. Pain medication was measured as medications dispensed that fell within BNF chapter 4 section 7 (analgesics). Mental health medication was measured as medications dispensed that fell within BNF chapter 4 paragraph 1 (hypnotics and anxiolytics); chapter 4 paragraph 2 (drugs used in psychoses and related disorders); and chapter 4 paragraph 3 (antidepressant drugs).

\section{Deprivation}


Deprivation was included as a variable in the model, and was measured using the NI Multiple Deprivation Measure (MDM). The MDM is a composite measure of the level of deprivation, made up of 7 domains, including income; employment; health and disability; education, skills and training; proximity to services; crime and disorder; and living environment (NISRA, 2010). The MDM was measured at super output level, from which categorical variables were constructed linking the individuals postcode to the MDM decile, with decile 1 comprising the most deprived areas and decile 10 comprising the least deprived areas.

\section{Ethical considerations}

To ensure the safe and secure use of the data, and to ensure confidentiality is maintained, the data was accessed through the Health and Social Care NI Business Services Organisation's Honest Broker Service (HBS) (HSC Business Services Organisation, 2018). This service provides access to health service data held in the regional data warehouse for use in National Research Ethics Service approved studies. All data was anonymised by the HBS, with researchers only having access to the anonymised data, from which no individual patients can be identified. The anonymised linked dataset was provide to the research team for analysis in the HBS secure environment. All HBS outputs are subject to statistical disclosure control to protect patient confidentiality. This process ensures the security and confidentiality of patient data, whilst facilitating beneficial research. The study was approved by the Brighton and Sussex Research Ethics Committee (REC Reference: 16/LO/1923).

\section{Statistical Analysis}

Statistical analyses were carried out using the R statistical programming language. The data was analysed using descriptive statistics and conditional logistic regression. Descriptive statistics were produced showing each of the variables broken down by the case and control groups. To analyse the relationships between the variables, we built four sets of models using conditional logistic regression. The first crude model focuses on the bivariate relationship 
between each predictor variable and death by suicide. The second model focuses on the relationship between mental health medication and suicide, whilst controlling for MDM. The third focuses on the relationship between pain medication and death by suicide, also controlling for MDM. The fourth model presents the full results, including both pain and mental health medication, whilst controlling for MDM.

\section{Results}

The descriptive statistics for the case and control groups are shown in table 1. One-thousand, one hundred and five people died by suicide in NI between $1 / 1 / 2012$ and 31/12/2015, who were matched to 5525 live controls. The descriptive statistics show that death by suicide most frequently occurs in males, and between the ages of 20 and 54. Death by suicide is most frequent in people living in the most deprived areas of NI, with almost $21 \%$ occurring in the first decile, compared with just under 5\% in the least deprived decile. Compared with the control group, a higher proportion of the case group received recent prescriptions for both mental health and pain medication. Just over $70 \%$ of the case group were prescribed mental health medication in the two years prior to death, with $57 \%$ of people receiving their most recent prescription within the three months prior to death. In comparison, mental health medication was prescribed to just under a quarter of the control group within the past two years. Over $50 \%$ of the case group received prescriptions for pain medication within the two years prior to death, compared to $27.7 \%$ of the control group.

\section{[INSERT TABLE 1 ABOUT HERE]}

Table 2 shows the results of the regression analyses which tested the significance of the patterns observed in the descriptive statistics. People who received their most recent prescription for mental health within the past two years were significantly more likely to die by suicide. This relationship exists across all time bands considered, with the highest odds of death by suicide for those receiving their most recent prescription within the past three 
months (odds=12.20), with the odds of death decreasing the further back in time the most recent mental health medication was prescribed. This pattern also remained across the full model when controlling for pain medication and deprivation. The crude model also highlights the relationship between pain medication prescription and death by suicide across all time bands. People prescribed pain medication within the past three months had the highest odds of death by suicide (3.69). However, unlike the mental health medication, the pattern of decreasing odds the further back the medication was most recently prescribed is less clear, with higher odds of death for those most recently prescribed 9-12 months prior to death (odds $=2.31$ ) compared with the 6-9 months prior to death (odds=1.88). Moreover, in the full models the relationship between the most recent pain medication prescription and death by suicide is not significant beyond nine months. Our models also control for deprivation, with the results indicating that suicide is more likely in areas that are more deprived, compared to the less deprived areas in NI.

\section{[INSERT TABLE 2 ABOUT HERE]}

\section{Discussion}

Previous studies of medication use and death by suicide in NI were based on descriptive data from coronial files, which may not have included extensive medication histories (Benson et al., 2017). This was the first study to assess the relationship between death by suicide and prescribed medication, using a matched comparison group and specifically examining pain medications alongside mental health medications. The findings demonstrate very high levels of the use of prescribed mental health medication in the two years prior to death $(70 \%$ in the suicide group and under a quarter of the control group).

The proportion in the suicide cases is higher than the $51.7 \%$, that was reported in a previous analysis of over 1600 suicides in NI (Benson et al., 2017), and also higher than the $57.6 \%$ who were recoded as having a mental disorder (O’Neill, Corry, Murphy, Brady \& 
Bunting, 2014). The study of coronial files was based on data up to 2011, and these differences may suggest that people are now more likely to disclose mental illness, and/ or that medication is now a more commonly used treatment. However, if we look at the figures for a 3-month period, the proportions are similar, therefore demonstrating the importance of examining medication prescription over a longer period of time. The figure for the control group (under a quarter) is also much higher than the $14.9 \%$, who were estimated to be using prescribed medication for mental health problems in the 2008 Northern Ireland Study of Health and Stress (Benson et al., 2015). Whilst the groups are different, it would be useful to examine whether there is an increase in the use of medications for mental illness from 2008 to the present.

Recent contact with a clinician is evidenced by the fact that $57 \%$ of those who died by suicide had received their most recent prescription within the three months prior to death. Contact with a clinician may have presented an opportunity for intervention. These findings indicate the importance of suicide assessment (and evidence-based suicide specific treatments) for people who are receiving prescribed medication for a mental illness. However healthcare professionals may not have the opportunity to prescribe, monitor or manage a client's medication use and therefore collaborative working is required to provide holistic suicide prevention care.

Over $50 \%$ of those who died by suicide received prescriptions for pain medication within the two years prior to death, compared to $27.7 \%$ of the control group. These figures further demonstrate the associations between suicide and pain related conditions, and physical health difficulties (Calati, Laglaoui, Bakhiyi, Artero, Ilgen \& Courtet, 2015). In the study of over 1600 suicide deaths based on data from coronial records, around a third of those who died by suicide had a recorded physical disorder (O'Neill et al., 2014), and 45.2\% had received medication for a physical health difficulty (Benson et al., 2017). Physical health 
problems were more common in the older age groups (O’Neill, Ennis, Corry \& Bunting, 2017).

The findings are in keeping with the conceptualisation of suicidal behaviour as a response to psychological pain (Elman et al., 2013, Franklin et al., 2017, Meerwijk \& Weiss, 2017, O’Connor \& Nock, 2014, Shneidman, 1993). The results from this study suggests that individuals in suicidal pain may present to health care providers with physical pain, which may be related to a chronic physical condition. Alternatively, they may use pain medications to alleviate their mental health symptoms, or indeed have a physiological dependence on pain medications. Pain is a commonly reported reason for self-harm, and there is emerging evidence for the links between mental illness and physical conditions including pain and inflammation generally (Rizvi et al., 2017, Sartorius, 2018). Whilst further research is required to extrapolate the associations between suicidal behaviour and pain, the current findings indicate a need for health care providers to exercise vigilance and ask people with pain related conditions, or who use medication for pain, about suicidal thoughts.

This study showed that death by suicide was more likely when the person had been prescribed medication recently, confirming previous studies showing the strong link between mental disorders and suicidal behaviour (Large et al., 2017, O’Connor \& Nock, 2014, VanOrden et al., 2010), and the link with medication treatment onset (Wasserman et al., 2012). Nonetheless, people who have been prescribed mental health medication any time within the past two years were more at risk of death by suicide, even if the medication was most recently prescribed over a year ago. Therefore the findings suggest that people who have been prescribed psychotropic medications are at risk for up to two years after their last prescription and may be suicidal even if they are not currently undergoing treatment. In these cases the suicide may be related to a recurrence of mental illness that was not currently being treated, or it may be that the illness is persisting after treatment has stopped, or the person 
stopped taking their medication too soon. This could indicate that a longer follow up period is required in the treatment of mental health conditions.

A different pattern emerged with regards to pain medication, with the likelihood of death by suicide being higher only for those who had been prescribed pain medication up to nine months previously. This suggests that current, or more recent pain is associated with suicidal behaviour and that this risk reduces with physical recovery and stopping medication. These is also a possibility that pain medication was used in some cases of suicide by overdose. In O'Neill et al's (2017) analysis of suicides based on coronial data $40.5 \%$ of women in the 41-60 age groups and almost $30 \%$ of the $21-40$ and $60+$ age groups died by overdose.

The association between death by suicide and area level deprivation is as expected. Compared to the most deprived decile, suicide is less likely in the less deprived areas. The prescription of psychotropic medication and pain medication was common among those in the matched control group, as well as the group of people who had died by suicide.

This study found high levels of prescriptions for both categories of medications in the control group as well as among those who died by suicide. NI is known to have one of the highest rates of prescribed medication use in the Western world. Although only reported in relation to anti-depressant, NI has consistently had significantly higher medication prescription with costs per head of population at $£ 1.71$ compared with $£ 0.41$ in Scotland and $£ 0.26$ in Wales (Donnelly, 2014).

The study has several limitations that need to be considered. Those who had received prescriptions for medications may not have taken the medications as recommended. Indeed analysis of toxicology reports indicated that medication non-adherence was common among people who died by suicide in the Benson et al. (2017) study. Furthermore, people in both groups may have acquired medications without a prescription. The misuse of prescription 
medication is a recognised problem in NI with a third of those in the Department of Health's substance misuse database reporting taking opioid painkillers (Department of Health, 2018). These findings illustrate the importance of interpreting these research findings in the context of local intelligence about trends in substance use, and the importance of involving local service providers in suicide prevention initiatives. Death by suicide is also associated with a range of other variables, including personal crises that were not examined in this study. Population surveillance programmes and psychological autopsy studies are required to understand the impact of these variables on risk of death by suicide, and the interactions with medication use and deprivation in NI specifically given the unique social and historical context. In addition, theorists are developing an increased recognition of the importance of studying of protective factors such as hope, positive future thinking, and reasons for living (Franklin et al., 2017, O’Connor \& Nock, 2014). These would be useful to consider in further studies, particularly in terms of the beneficial effects of pharmacological interventions. The psychological factors should certainly not be abandoned. However, they are often difficult to identify in practice, especially when taking into account the range of other healthcare professionals who may be working with the patient. Prescription medication offers an additional means of identifying people who may benefit from further assessment.

\section{Acknowledgements}

The authors would like to acknowledge the help provided by the staff of the Honest Broker Service (HBS) within the Business Services Organisation NI (BSO). The HBS is funded by the BSO and the Department of Health (DoH). The authors alone are responsible for the interpretation of the data and any views or opinions presented are solely those of the author and do not necessarily represent those of the BSO. 


\section{References}

Benson T, et al. (2017). Use of prescription medication by individuals who died by suicide in Northern Ireland. Archives of Suicide Research, 0, 1-14.

Benson T, et al. (2015). Prevalence and predictors of psychotropic medication use: results from the Northern Ireland Study of Health and Stress. Epidemiology and Psychiatric Sciences, 24, 542-552.

BNF (2018). B NF Publications. Retrieved from: www.bnf.org

Calati R, et al. (2015). The impact of physical pain on suicidal thoughts and behaviors: Meta-analyses. J Psychiatr Res., 71, 16-32.

Cipriani A, et al. (2018). Comparative efficacy and acceptability of 21 antidepressant drugs for the acute treatment of adults with major depressive disorder: a systematic review and network meta-analysis. The Lancet, 2018

Department of Health (2018). Statistics from the Northern Ireland Substance Misuse Database:1 April 2016 - 31 March 2017. Department of Health, 2018 (https://www.health-ni.gov.uk/sites/default/files/publications/health/smd-2016-17.pdf).

Department of Health (2016). Protect Life 2: A Draft Strategy for Suicide Prevention in the North of Ireland. Retrieved from: https://www.healthni.gov.uk/sites/default/files/consultations/health/protect-life-2-consultation.pdf

Donnelly, K.J. (2014). Primary Care Prescribing. Northern Ireland Audit Office: Belfast. Retrieved from: http://www.niauditoffice.gov.uk/primary_care_prescribing-2.pdf

Dougall N, et al. (2014). Deaths by suicide and their relationship with general and psychiatric hospital discharge: 30-Year record linkage study. Br J Psychiatry., 204, 267-273.

Elman I, et al. (2013). Pain and suicidality: Insights from reward and addiction neuroscience. Prog Neurobiol., 109, 1-27. 
Escobar JI, et al. (2006). Idiopathic physical symptoms: A common manifestation of psychiatric disorders in primary care. CNS Spectrums, 11, 201-210.

Franklin JC, et al. (2017). Risk factors for suicidal thoughts and behaviors: A meta-analysis of 50 years of research. Psychological Bulletin, 143, 187-232.

Gibbons RD, et al. (2012). Suicidal thoughts and behavior with antidepressant treatment: Reanalysis of the randomized placebo-controlled studies of fluoxetine and venlafaxine. Archives of General Psychiatry, 69, 580-587.

HSC Business Services Organisation. Honest Broker Service (2018). Retrieved from: http://www.hscbusiness.hscni.net/services/2454.htm

Klonsky ED and May AM (2014). Differentiating suicide attempters from suicide ideators; a critical frontier for suicidology research. Suicide and Life-threatening Behaviour, 44, $1-5$.

Large MM, et al. (2017). Uncertainties: Can we usefully stratify patients according to suicide risk? BMJ-British Medical Journal 2017; 359: j4627.

Largey M, Kelly CB and Stevenson M (2009). A study of suicide rates in Northern Ireland 1984-2002. Ulster Medical Journal, 78, 16-20.

Lavigne JE (2016). Suicidal ideation and behavior as adverse events of prescribed medications: An update for pharmacists. J Am Pharm Assoc., 56, 203-6.

Lavigne, J. E., McCarthy, M., Chapman, R., Petrilla, A., \& Knox, K. L. (2012). Exposure to prescription drugs labeled for risk of adverse effects of suicidal behavior or ideation among 100 air force personnel who died by suicide, 2006-2009. Suicide and LifeThreatening Behavior, 42, 561-566.

Lewis G and Sloggett A (1998). Suicide, deprivation, and unemployment: record linkage study. BMJ, 317, 1283-1286. 
Meerwijk EL and Weiss SJ (2017). Utility of a time frame in assessing psychological pain and suicide ideation. PeerJ., 5, e3491.

NISRA. (2012). Suicide Statistics in Northern Ireland: Impact of Time Taken to Investigate the Death. Northern Ireland Statistics Research Agency, 1-8.

NISRA (2010). Northern Ireland Multiple Deprivation Measure 2010. Northern Ireland Statistics and Research Agency, (May), 1-24. Retrieved from https://www.nisra.gov.uk/sites/nisra.gov.uk/files/publications/NIMDM_2010_descripti on_of_indicators_domains_and_the_multiple_deprivation_measure.pdf NISRA (2017). Number of suicides registered each calendar year in Northern Ireland. Northern Ireland Statistics and Research Agency, 2017. Retrieved from: https://www.nisra.gov.uk/publications/suicide-statistics.

O'Connor RC and Nock MK (2014). The psychology of suicidal behaviour. Lancet Psychiatry, 1, 73-85.

ONS (2017). Suicides in Great Britain: 2016 registrations. Retrieved from:

https://www.ons.gov.uk/peoplepopulationandcommunity/birthsdeathsandmarriages/deat hs/bulletins/suicidesintheunitedkingdom/2016registration

O’Neill S, et al. (2014). Characteristics of deaths by suicide in Northern Ireland from 2005 to 2011 and use of health services prior to death. J Affect Disord., 168, 466-71.

O’Neill S, et al. (2017). Factors associated with suicide in four age groups: a population based study. Archives of Suicide Research, 0, 1-11.

Pouliot L and DeLeo D (2006). Critical issues in psychological autopsy studies. Suicide \& Life-Threatening Behavior, 36, 491-510.

Rizvi SJ, et al. (2017). Psychological and physical pain as predictors of suicide risk: evidence from clinical and neuroimaging findings. Current Opinion in Psychiatry, 30, $159-167$. 
Samaritans (2017). Suicide Statistics Report 2017. Retrieved from:

https://www.samaritans.org/sites/default/files/kcfinder/files/Suicide_statistics_report_2 017_Final.pdf

Sartorius N (2018). Comorbidity of mental and physical disorders: a key problem for medicine in the $21^{\mathrm{s}}$ century. Acta Psychiatrica Scandinavica, 137, 369-370.

Shneidman ES (1993). Suicide as psychache: A clinical approach to self-destructive behavior. Lanham, MD, US: Jason Aronson.

Sharma T, et al. (2016). Suicidality and aggression during antidepressant treatment: Systematic review and meta-analyses based on clinical study reports. BMJ, 352, i65.

The detail (no date). The Script Report. Retrieved from: http://script-report.thedetail.tv.

Van Orden KA, et al. (2010). The interpersonal theory of suicide. Psychol Rev., 117, 575600.

Verrocchio MC, et al. (2016). Mental pain and suicide: A systematic review of the literature. Frontiers in Psychiatry, 7, 108.

Voaklander DC, et al. (2008). Medical illness, medication use and suicide in seniors: a population-based case-control study. J Epidemiol Community Health, 62, 138-146.

Wasserman D, et al. (2012). The European Psychiatric Association (EPA) guidance on suicide treatment and prevention. European Psychiatry, 27, 129-141. 
Table 1: Descriptive Statistics

\begin{tabular}{|c|c|c|c|c|c|}
\hline Variable & Case (n) & Control (n) & Total (n) & Case $\%$ & Control \% \\
\hline \multicolumn{6}{|l|}{ Age, years } \\
\hline 10 to 19 & 55 & 364 & 419 & 4.98 & 6.59 \\
\hline $20-24$ & 111 & 472 & 583 & 10.05 & 8.54 \\
\hline $25-29$ & 131 & 637 & 768 & 11.86 & 11.53 \\
\hline 30-34 & 124 & 581 & 705 & 11.22 & 10.52 \\
\hline $35-39$ & 114 & 587 & 701 & 10.32 & 10.62 \\
\hline $40-44$ & 110 & 609 & 719 & 9.95 & 11.02 \\
\hline $45-49$ & 129 & 583 & 712 & 11.67 & 10.55 \\
\hline $50-54$ & 111 & 539 & 650 & 10.05 & 9.76 \\
\hline $55-59$ & 74 & 406 & 480 & 6.70 & 7.35 \\
\hline $60-64$ & 62 & 286 & 348 & 5.61 & 5.18 \\
\hline $65-69$ & 38 & 220 & 258 & 3.44 & 3.98 \\
\hline $70-74$ & 20 & 114 & 134 & 1.81 & 2.06 \\
\hline over75 & 26 & 127 & 153 & 2.35 & 2.30 \\
\hline \multicolumn{6}{|l|}{ Gender } \\
\hline Female & 268 & 1340 & 1608 & 24.25 & 24.25 \\
\hline Male & 837 & 4185 & 5022 & 75.75 & 75.75 \\
\hline \multicolumn{6}{|c|}{ Multiple Deprivation Measure, Decile } \\
\hline 1 (most deprived) & 230 & 587 & 817 & 20.81 & 10.62 \\
\hline 2 & 147 & 563 & 710 & 13.30 & 10.19 \\
\hline 3 & 122 & 558 & 680 & 11.04 & 10.10 \\
\hline 4 & 121 & 606 & 727 & 10.95 & 10.97 \\
\hline 5 & 97 & 540 & 637 & 8.78 & 9.77 \\
\hline 6 & 94 & 548 & 642 & 8.51 & 9.92 \\
\hline 7 & 81 & 503 & 584 & 7.33 & 9.10 \\
\hline 8 & 101 & 558 & 659 & 9.14 & 10.10 \\
\hline 9 & 50 & 537 & 587 & 4.52 & 9.72 \\
\hline 10 (least deprived) & 52 & 476 & 528 & 4.71 & 8.62 \\
\hline \multicolumn{6}{|c|}{ Most recent mental health medication prescribed in past } \\
\hline$>0-\leq 3$ months & 637 & 778 & 1415 & 57.65 & 14.08 \\
\hline$>3-\leq 6$ months & 47 & 110 & 157 & 4.25 & 1.99 \\
\hline$>6-\leq 9$ months & 27 & 71 & 98 & 2.44 & 1.28 \\
\hline$>9-\leq 12$ months & 19 & 76 & 95 & 1.72 & 1.38 \\
\hline$>12-\leq 24$ months & 46 & 237 & 283 & 4.16 & 4.29 \\
\hline None within 24 months & 329 & 4253 & 4582 & 29.77 & 76.98 \\
\hline \multicolumn{6}{|c|}{ Most recent pain medication prescribed in past } \\
\hline$>0-\leq 3$ months & 313 & 632 & 945 & 28.33 & 11.44 \\
\hline$>3-\leq 6$ months & 70 & 206 & 276 & 6.33 & 3.73 \\
\hline$>6-\leq 9$ months & 43 & 174 & 217 & 3.89 & 3.15 \\
\hline$>9-\leq 12$ months & 36 & 117 & 153 & 3.26 & 2.12 \\
\hline$>12-\leq 24$ months & 99 & 399 & 498 & 8.96 & 7.22 \\
\hline None within 24 months & 544 & 3997 & 4541 & 49.23 & 72.34 \\
\hline
\end{tabular}


Table 2: Regression Analysis - dependent variable is died by suicide (1) / alive (0)

\begin{tabular}{|c|c|c|c|c|c|c|c|c|}
\hline \multirow[t]{2}{*}{ Variable } & \multicolumn{2}{|c|}{ Crude $^{a}$} & \multicolumn{2}{|c|}{$\begin{array}{l}\text { Mental Health } \\
\text { Medication }^{\mathbf{b}}\end{array}$} & \multicolumn{2}{|c|}{$\begin{array}{l}\text { Pain } \\
\text { Medication }^{c}\end{array}$} & \multicolumn{2}{|c|}{ Full Model $^{d}$} \\
\hline & Odds & $95 \% \mathrm{Cl}$ & Odds & $95 \% \mathrm{Cl}$ & Odds & $\begin{array}{l}95 \% \\
\mathrm{Cl}\end{array}$ & Odds & $\begin{array}{l}95 \% \\
\mathrm{Cl}\end{array}$ \\
\hline \multicolumn{9}{|c|}{ Most recent mental health medication prescribed in past ${ }^{\mathrm{e}}$} \\
\hline$>0-\leq 3$ months & $13.00 * * *$ & $\begin{array}{l}10.88- \\
15.51\end{array}$ & $12.20 * * *$ & $\begin{array}{l}10.19- \\
14.61\end{array}$ & & & $10.95 * * *$ & $\begin{array}{l}9.06- \\
13.24\end{array}$ \\
\hline$>3-\leq 6$ months & $6.39 * * *$ & $\begin{array}{l}4.38- \\
9.33\end{array}$ & $5.78^{* * *}$ & $\begin{array}{l}3.92- \\
8.52\end{array}$ & & & $5.20 * * *$ & $\begin{array}{l}3.52- \\
7.68\end{array}$ \\
\hline$>6-\leq 9$ months & $5.54^{* * *}$ & $\begin{array}{l}3.43- \\
8.95\end{array}$ & $5.21 * * *$ & $\begin{array}{l}3.19- \\
8.50\end{array}$ & & & $4.78^{* * *}$ & $\begin{array}{l}2.92- \\
7.84\end{array}$ \\
\hline$>9-\leq 12$ months & $3.65^{* * *}$ & $\begin{array}{l}2.13- \\
6.23\end{array}$ & $3.76^{* * *}$ & $\begin{array}{l}2.19- \\
6.45\end{array}$ & & & $3.44^{* * *}$ & $\begin{array}{l}1.98- \\
6.00\end{array}$ \\
\hline $\begin{array}{l}>12-\leq 24 \\
\text { months }\end{array}$ & $2.83 * * *$ & $\begin{array}{l}1.99- \\
4.02\end{array}$ & $2.60 * * *$ & $\begin{array}{l}1.81- \\
3.73\end{array}$ & & & $2.47^{* * *}$ & $\begin{array}{l}1.72- \\
3.55\end{array}$ \\
\hline \multicolumn{9}{|c|}{ Most recent pain medication prescribed in past ${ }^{\mathrm{e}}$} \\
\hline$>0-\leq 3$ months & $4.07 * * *$ & $\begin{array}{l}3.42- \\
4.83\end{array}$ & & & $3.69 * * *$ & $\begin{array}{l}3.10- \\
4.41\end{array}$ & $1.44 * * *$ & $\begin{array}{l}1.17- \\
1.78\end{array}$ \\
\hline$>3-\leq 6$ months & $2.69 * * *$ & $\begin{array}{l}2.01- \\
3.60\end{array}$ & & & $2.58 * * *$ & $\begin{array}{l}1.92- \\
3.46\end{array}$ & $1.74^{*}$ & $\begin{array}{l}1.25- \\
2.43\end{array}$ \\
\hline$>6-\leq 9$ months & $1.99 * * *$ & $\begin{array}{l}1.40- \\
2.83\end{array}$ & & & $1.88 * * *$ & $\begin{array}{l}1.35- \\
2.69\end{array}$ & $1.28 * *$ & $\begin{array}{l}0.86- \\
1.91\end{array}$ \\
\hline $\begin{array}{l}>9-\leq 12 \\
\text { months }\end{array}$ & $2.42^{* * *}$ & $\begin{array}{l}1.64- \\
3.55\end{array}$ & & & $2.31 * * *$ & $\begin{array}{l}1.56- \\
3.41\end{array}$ & 1.19 & $\begin{array}{l}0.76- \\
1.86\end{array}$ \\
\hline $\begin{array}{l}>12-\leq 24 \\
\text { months }\end{array}$ & $1.94^{* * *}$ & $\begin{array}{l}1.52- \\
2.47\end{array}$ & & & $1.90 * * *$ & $\begin{array}{l}1.49- \\
2.43\end{array}$ & 1.41 & $\begin{array}{l}1.06- \\
1.86\end{array}$ \\
\hline \multicolumn{9}{|c|}{ Multiple Deprivation Measure, Decile ${ }^{f}$} \\
\hline 2 & $0.67 * * *$ & $\begin{array}{l}0.52- \\
0.84\end{array}$ & $0.73^{*}$ & $\begin{array}{l}0.55- \\
0.96\end{array}$ & $0.70 * *$ & $\begin{array}{l}0.55- \\
0.90\end{array}$ & $0.73^{*}$ & $\begin{array}{l}0.55- \\
0.96\end{array}$ \\
\hline 3 & $0.55^{* * *}$ & $\begin{array}{l}0.43- \\
0.71\end{array}$ & $0.68^{* *}$ & $\begin{array}{l}0.50- \\
0.90\end{array}$ & $0.61 * * *$ & $\begin{array}{l}0.47- \\
0.79\end{array}$ & $0.70^{*}$ & $\begin{array}{l}0.52- \\
0.93\end{array}$ \\
\hline 4 & $0.50 * * *$ & $\begin{array}{l}0.39- \\
0.64\end{array}$ & $0.59 * * *$ & $\begin{array}{l}0.44- \\
0.78\end{array}$ & $0.58 * * *$ & $\begin{array}{l}0.45- \\
0.75\end{array}$ & $0.61 * * *$ & $\begin{array}{l}0.46- \\
0.82\end{array}$ \\
\hline 5 & $0.45^{* * *}$ & $\begin{array}{l}0.35- \\
0.59\end{array}$ & $0.53^{* * *}$ & $\begin{array}{l}0.38- \\
0.71\end{array}$ & $0.51 * * *$ & $\begin{array}{l}0.39- \\
0.67\end{array}$ & $0.54^{* * *}$ & $\begin{array}{l}0.40- \\
0.74\end{array}$ \\
\hline 6 & $0.43^{* * *}$ & $\begin{array}{l}0.33- \\
0.56\end{array}$ & $0.54 * * *$ & $\begin{array}{l}0.40- \\
0.74\end{array}$ & $0.49 * * *$ & $\begin{array}{l}0.37- \\
0.64\end{array}$ & $0.57^{* * *}$ & $\begin{array}{l}0.42- \\
0.77\end{array}$ \\
\hline 7 & $0.40 * * *$ & $\begin{array}{l}0.30- \\
0.53\end{array}$ & $0.51 * * *$ & $\begin{array}{l}0.37- \\
0.71\end{array}$ & $0.47^{* * *}$ & $\begin{array}{l}0.35- \\
0.62\end{array}$ & $0.54^{* * *}$ & $\begin{array}{l}0.39- \\
0.74\end{array}$ \\
\hline 8 & $0.46 * * *$ & $\begin{array}{l}0.35- \\
0.59\end{array}$ & $0.63^{* *}$ & $\begin{array}{l}0.47- \\
0.86\end{array}$ & $0.53 * * *$ & $\begin{array}{l}0.41- \\
0.70\end{array}$ & $0.66 * *$ & $\begin{array}{l}0.49- \\
0.90\end{array}$ \\
\hline 9 & $0.24^{* * *}$ & $\begin{array}{l}0.17- \\
0.33\end{array}$ & $0.35 * * *$ & $\begin{array}{l}0.24- \\
0.50\end{array}$ & $0.28 * * *$ & $\begin{array}{l}0.20- \\
0.40\end{array}$ & $0.34 * * *$ & $\begin{array}{l}0.25- \\
0.52\end{array}$ \\
\hline $\begin{array}{l}10 \text { (least } \\
\text { deprived) }\end{array}$ & $0.27^{* * *}$ & $\begin{array}{l}0.20- \\
0.38\end{array}$ & $0.38 * * *$ & $\begin{array}{l}0.27- \\
0.55\end{array}$ & $0.35^{* * *}$ & $\begin{array}{l}0.25- \\
0.49\end{array}$ & $0.41 * * *$ & $\begin{array}{l}0.28- \\
0.59\end{array}$ \\
\hline
\end{tabular}

${ }^{a}$ Adjusted for age and gender based on matching criteria

${ }^{\mathrm{b}}$ Adjusted for age, gender, and mental health medication use and MDM

${ }^{\mathrm{C}}$ Adjusted for age, gender, and pain medication use and MDM

${ }^{\mathrm{d}}$ Adjusted for age, gender, mental health medication use, pain medication use, and MDM 
e The reference category for pain and mental health medication is 'Not Prescribed Within 24 Months' ${ }^{f}$ The reference category for MDM is 1 , which is the decile with the highest level of deprivation. 


\section{Highlights}

- Odds ratios for death by suicide linked to recency of prescription

- Links were for both mental health medications and pain medications

- Suicide is more likely in areas that are more deprived

- Clinician contact to obtain prescription may allow intervention 